\title{
HOW LONG DOES IT TAKE TO BUILD AN APARTMENT?
}

\author{
Sigmund Aslesen ${ }^{1}$, Sigmund Reff $^{2}$, and Espen Stordal ${ }^{3}$
}

\begin{abstract}
This paper explores how long it takes to build an apartment. In our effort to answer the question, we concentrate on the inventory phase. The phase involves the completion of every apartment. It includes several trades, a significant number of tasks and a great deal of coordination, and spans from erecting the walls to installing and coupling of technical systems and to the finishing of kitchen, bathroom(s), doors and all surfaces.

The paper is grounded in the research idea that to make construction more like manufacturing, we need to study it from a manufacturing viewpoint. Its starting point are the peculiarities of construction as emphasized by one-of-a-kind projects, site production, a temporary organization and intervention of regulatory authorities (Koskela 1992). While these particularities have played a fundamental role to understand the uniqueness of the construction building process, we argue in this paper to handle them with caution so that they do not hamper initiatives - and insights - based on the commonalities of the two types of production.

In the paper, a preliminary analysis is carried out based on a housing project including 127 apartments, divided by four, four-to-six storey high blocks. Using the single apartment as the production unit, we outline certain assessments which we plan to test full-scale in a sizeable housing project including 342 apartments. The paper discusses the potential benefits of defining an apartment as the production unit, and how it may assist production knowing how long it takes to build an apartment. We conclude that to build an apartment in a more effective and less wasteful manner than today, we should think of it as more of a manufacturing than a construction process.
\end{abstract}

\section{KEYWORDS}

Production planning and control, theory.

\section{INTRODUCTION}

How long does it take to build an apartment? In any housing project of a certain size, estimating the time to complete an apartment may help planning the total duration of the project. Using the apartment as the unit of production also makes sense from a customer point of view, since in housing projects the single flat is what is handed over to the end user. In our attempt to answer the question, we have decided to limit our attention to the

${ }^{1}$ Development Manager, Veidekke, Oslo, Norway, +47 92218 492, sigmund.aslesen@ veidekke.no

${ }^{2}$ Site Manager, Veidekke, Oslo, Norway, +47 41463 193, sire@ veidekke.no

${ }^{3}$ Project Manager, Veidekke, Oslo, Norway, +47 40848 482, espen.stordal@ veidekke.no 
inventory part of the construction process. Although leaving out other parts of the construction production implies a major simplification, we find the inventory phase more easily comparable to the assembly of products going on in manufacturing.

The authors work for a Norwegian general contractor involved in all kinds of construction and civil engineering. In the Oslo unit where we are employed, housing projects make up 40 per cent of the total turnover. On a yearly basis, we complete around 1000 apartments. In the housing production, we use a core of trade workers from our own company to do the concrete, carpentry and bricklaying parts of the job, while the technical work and other jobs are hired on a project basis. However, due to the volume of different jobs and for strategic reasons as well, we often end up with many of the same suppliers across projects. As for the clients, a few dominate the housing market in the Oslo area. This implies that over the years we have taken on numerous projects for much of the same clients. Consequently, we have earned considerable knowledge and experience about their preferences in the product. The combination of recurring clients, a voluminous housing production, the use of own workers and a network of suppliers and subcontractors, is what makes the question in the paper's title particularly relevant for us.

What kind of production is construction? This question was raised several years ago by Ballard and Howell (1998), in a paper holding the very same title. It was based in the belief that construction is a fundamentally different kind of production. We argue that there is no simple answer to that question, since it may vary substantially between different types of projects. Furthermore, that the character of the answer will depend on the level of observation. While every project is unique somehow, we think that to start by focusing on the uniqueness may easily lead to a tautological reasoning where every project - and thereby construction production - is said to have the same qualities. In the paper, we use a case study including one project only to do a preliminary analysis. The unit of investigation is not the housing project per se, but the completion of apartments going on as part of it. Our point of departure is this; that the production of housings, even though being conducted on site, has clear parallels to manufacturing production and that we have far more to gain by seeing them as akin rather than as counterparts.

\section{THEORY}

In 1992, Lauri Koskela published his study of what was called a new production philosophy and its application to construction (1992). The term "new production philosophy" here referred to the set of methodologies, techniques and tools evolved in Japanese car manufacturing, under the concepts of just-in-time, total quality management, world class manufacturing and Lean Production. The goal of his research was to assess whether this new production philosophy had implications for construction. Koskela concluded that construction should adopt the new production philosophy. His reasoning was based on seeing construction as flow processes and not only as a series of conversion activities. At the same time, an effort to overcome flow problems was needed to improve the construction production, which incorporated an understanding of its peculiarities (op.cit, p. 44). These peculiarities were: 1) the one-of-a-kind nature of construction projects caused by differing needs and priorities of the client, differing sites and surroundings, and differing 
views of designers on the best solutions, 2) site production, the way construction production is typically carried out at the final site of the constructed product, 3) temporary multiorganization, implying that a construction project organization is usually a temporary organization made up by different companies and practices, which have not necessarily worked together before and which are tied together by means of varying contractual arrangement, and 4) intervention of regulatory authorities, in design solutions and many work phases where the project is subject to checking and approval.

The peculiarities of construction production articulated by Koskela (1992) have later worked as guidelines or rules for the many who have approached Lean Construction with the aim to increase their understanding of the industry, or to improve it - in most cases both. Ballard and Howell (1998), two of the other founding fathers of Lean Construction, go as far as to state that we must learn how to manage uncertainty and complexity and quickness within these characteristic construction conditions. Their reasons for saying so are founded partly in the elaboration of various types of manufacturing, and partly from seeing construction as directives-driven where a key to efficient assembly is production planning and control. Ballard and Howell (op.cit) conclude by advocating a two-part implementation strategy, whereof one part consists of minimizing construction peculiarities to take advantage of lean techniques developed in manufacturing, and the other part includes to develop lean techniques adequate to dynamic construction.

Now, more than 20 years later, it is reasonable to say that the research and development initiated in the Lean Construction sphere has been fundamentally dominated by the developing of lean techniques adequate to dynamic construction. In doing so, one risks only coming halfway since taking advantage of lean techniques should also imply to look to manufacturing for improvements. There are, indeed, some important exceptions worth mentioning. A number of papers brings up the management of the construction supply chain and just-in-time deliveries (Vrijhof and Koskela 1999; Zimmer, Salem, Genaidi and Shell 2008), prefabrication (Ballard, Harper and Zabelle 2002; Ballard and Arbulu 2004; Höök and Stehn 2005) and off-site manufacturing (Pasquire and Connolly 2002, 2003), value stream mapping (Picchi and Granja 2004), modularization and industrialization (Bertelsen 2005; Lessing, Stehn and Ekholm 2005; Hermes 2015), construction manufacturing (Pasquire, Soar and Gibb 2006), mass customization (Tillmann and Formoso 2008), work standardization (Mariz, Picchi, Granja and de Melo 2012) and last, but not least, takt time planning (Frandson, Berghede and Tommelein 2013; Frandson, Seppänen and Tommelein 2015; Binninger, Dlouhy and Hagsheno 2017).

Our theoretic starting point is from a paper on the categorization of production. Here, Bølviken (2012) presents a matrix including four different forms of production, which are categorized according to types of organizations and products. In the matrix, construction is conceptualized as project production recognized by unique products and a temporary organization while mass production works as some sort of counterpart recognized by similar products and a permanent organization. What triggered us was how a classification like this is very useful to explain construction production the way it works today, but that it falls short in suggesting any direction for future development of the industry. This is why we draw an imaginary line from project production in the lower right corner of the matrix, to mass production in the upper left corner. Our intention is to challenge the traditional 
view, also existing within our company, that everyday problems which tend to reappear on site are due to the very characteristics of construction production and therefore more or less inevitable. In line with Koskela's (1992) reasoning, we believe one should follow the lead of manufacturing by reconceptualizing construction as flows (p. 37). Understanding the peculiarities of construction is thereby quite another matter than using them as an excuse. Improvement is to be able to avoid or alleviate their detrimental effects (op.cit, p. 44).

Following the lead of manufacturing, the Toyota Production System is a forerunner. Its basic idea is the elimination of inventories and other waste by applying a range of techniques to make sure continuous improvement of both operations, equipment and processes (Liker and Meier 2006). Its conceptual basis is production as a flow of materials and/or information. In this flow, the material is processed (converted), it is inspected, it is waiting, or it is moving (Koskela 1992, p. 15). While all these activities expend cost and consume time, only conversion activities add value to the material being transformed to a product. In turn, improvement of flow activities (inspection, waiting, moving) should focus on their reduction or elimination, whereas conversion activities must be made more efficient (op.cit, p. 16). Does it make sense to think of the production of apartments in much the same way? We think so. The completion of an apartment is a flow of materials being transformed to a product - a flat. While the production is ongoing, the different rooms making up the apartment is transformed from a structural basis to a complete product. Several times during the production, the apartment is being inspected. For quite some time, it is also empty - meaning that nothing is going on and it awaits being further processed. A major difference, though, concerns the product - the flat - which does not move while the workers and their work stations do, as opposed to automotive production where the car moves while being processed in the various work cells along the assembly line.

Does it still make sense to compare housing with automotive production? Absolutely. To apply a categorization of production forms is not the same as being categorical. Bølviken (2012) implicitly explains this point when discussing the development of the Toyota Production System which, although having mass production as a starting point, was designed as an order-based system driven by market pull. If we use the same rationale on housing production, we may come to see it as - although taking place within a project being somewhat related to both mass and order production. This is important because seeing housing production as something else than just project-based production may trigger new thoughts about what should be the basic productivity strategy. According to Bølviken (2012), each production form in his matrix can be associated with a specific and basic productivity strategy. He goes on by referring to Ohno (1978), considered to be the father of the Toyota Production System, who described volume and standardization as the basic productivity strategy for mass production, and flow as the basis for order production. If we find the completion of apartments to be somewhere in between these two production forms, then the efforts to improve it should reflect its basic character. Although collaborative planning that includes all competencies - said to be basic productivity strategy for project production (Ballard 2000; Bølviken 2012) - will never be wrong and always be right, it may only bring you halfway when dealing with housing production to the point real challenges and characteristics are not sufficiently addressed. 


\section{METHODOLOGY}

The paper is based on a combination of field research and a factory visit to a manufacturing plant. The first author has, for 12 months, taken part full time in a housing project to observe, describe and analyse the ongoing production and its planning and control processes. As part of the apartment completion, he has had responsibilities related to the following up of all the mounting of parquet and kitchens involved in this production. He has predominantly been concerned with the progress of these tasks, and likewise in different ways helped to secure an even flow in the housing production. The second author is the project manager of the biggest housing project in the history of the company, where potentially more than 2500 apartments are to be built and where the designing of the apartments for the first stage - including 342 apartments - is based on high levels of standardization. The third author is the site manager of the same project and has considerable experience from similar roles in earlier housing projects.

Data is collected using direct observation, in combination with participation in meetings. The factory visit was done as part of a four-day, intensive course in Lean production and takt planning arranged by Porsche Consulting. The course took place on the shop floor in their manufacturing plant in Leipzig, Germany.

\section{RESEARCH}

\section{THROUGHPUT TIME}

Throughput time denotes the amount of time required for a product to go through a manufacturing process. It includes the time spent for processing, inspection, moving and waiting. In the Porsche manufacturing plant in Leipzig, a new Porsche Macan or Panamera rolls off the final assembly line every 3.8 minutes. The average daily production is 650 cars, which adds up to 150.000 cars a year. Behind this impressive production rate is a throughput time of 8 hours per car. It covers the entire period from the car enters the final assembly line until it exits this process. If we also count in the time in the body and paint shop, throughput time sums up to roughly 48 hours per car. In the housing project in study, the inventory phase for the 127 apartments spans over a period of 43 weeks altogether if holidays are excluded, or totally 215 working days. If we reckon a working year to consist of 230 days, around 136 apartments are completed on a yearly basis. The throughput time for an apartment is, however, much longer than the production rate should indicate. The time from an apartment is started on to its completion is between 70-80 days.

\section{WORK IN PROGRESS AND TAKT TIME}

The combination of a high production rate with a long throughput time implies that it, during the inventory phase of a housing project, is a substantial amount of work in progress. Work in progress refers to all apartments where the processing is started on, but not yet completed. This matter, because work in progress is not worth as much as completed work. Simultaneously, a housing project is not completed before all apartments are completed and the project can be handed over to the client. If a project can produce 136 apartments on a yearly basis, the monthly production rate would be around 11,3 apartments (holidays 
excluded). However, housing production, at least the way it works today, is an uneven form of production. It has a bell-shaped curve. A production peak is reached when there are activities going on in almost every floor, in every block. Then, the manning is high, the crews are many and the work in progress substantial, following that progress planning becomes essential to coordinate actions and maintain control.

Whereas in a machine-paced manufacturing line, a takt or "rhythm" is developed to match the capabilities of all work cells in that line and/or to adjust capabilities to the takt, in a housing project crews controlling each other's progress is a key to maintaining speed throughout the inventory phase. Every floor works as a control zone to check status on progress (and the subsequent takt), to adjust the manning if needed and to avoid being interrupted by other trades. Just as Porsche's final assembly line has many cars being processed at the same time in different work cells, the production of housings goes on in parallel. To be more concrete, the crew doing the listing may be occupied on the third floor of a block, while kitchens are mounted on the floor below, following the parquet guys who have started laying the floors on the first level while the electricians install plugs on the ground floor. This moreover addresses two important principles in the housing production. First, that the different crews prefer to start on top of a stair shaft and move downwards, to ease the transportation of their work stations. Second, that the apartments are processed in small batches, the way crews complete their job floor-by-floor.

\section{BUFFERS AND VARIATION}

Buffers are used to compensate for variations in the production process. A simple calculation based on the housing project's plan for the inventory phase shows that on a floor including four apartments, the total expected processing time - all activities included - is 54 days, which divided by four is 13,5 effective days per apartment. This means that of the total 70-80 days of throughput time for an apartment, there is likely work going on in that apartment for less than 20 per cent of the time. The gap between throughput time and processing time indicates that housing production is buffered. The buffers, we shall see, come in various forms.

Time buffers allow for a "slack" or "pause" in the production. In the housing production, time buffers are found as "rest days" in the progress plan. They are especially apparent in the early part of the inventory phase. It includes all the preparatory work to make the apartment ready for the later interior part and is predominantly made up of carpentry work related to the mounting of walls. In between this work are small in-wall tasks related to the installing of boxes, pipes, fuse box and other stuff by the electrician, the coupling of water and drain in the bathroom and kitchen by the plumber, and in addition some duct work. The preparatory work is almost like a production of its own. It resembles the body shop in the Porsche production where aluminium and steel parts are joined step by step to form the vehicle's metal coat. Even more so, because of the quality control regime characterizing both these production lines. Despite the high degree of automation in the Porsche body shop, human efforts are here essential to do quality controls and system operation testing. Likewise, inspections are done of the preparatory work to make sure everything is in the right place and function before the interior part is started on. In both cases, time buffers are allowed to have time to uncover errors and make the necessary corrections. 
The preparatory work goes on all the way to the sparkling of floors, which marks a split between the preparatory and interior part and which therefore functions as a milestone in the inventory phase. For the interior work, capacity buffers are inherent in the tasks and do not reveal themselves in the progress plan. A capacity buffer is when a crew is underloaded by setting aside more time to do a task than what is expected needed from that crew. This can happen for various reasons. The interior work involves many tasks, several trades and multiple interdependencies. Before kitchens are installed, painting and parquet must be done. Then, finishing goes on to make the apartment ready, by the installing of doors and listing, lighting and plugs, coupling of water and drain in kitchen, testing of various functions and so on. To calculate a certain surplus capacity may make it easier to handle the unforeseen, and still be on schedule. Maybe particularly so, because the task completions also follow a learning curve. A capacity buffer in the beginning can thus be a good strategy to keep the different crews from falling off the wagon. In addition, capacity buffers are counted in due to variation caused by differences in apartment size and additional choices made by the end users.

The sequential character of the interior work reminds of the final assembly line in Porsche's manufacturing plant. Here, you find work cells along the line performing standardized operations related to different completions. Time buffers are counted in, in between operations as every crew in each cell is provided with extra time to await and prepare for the next car on the line. As regards capacity buffers, the automotive production is much more finetuned to fit with the amount of operations in each cell so that the assembly line can hold an even pace all the way through this process. Besides, the variation in product mix has little impact on the assembly process since the processing times are balanced for different products.

\section{INDUSTRIALIZED PROCESSES}

A production rate of 136 apartments a year in a project would never be possible without the achievements to industrialize the housing production. Industrialization denotes the process whereby a manual based form of production becomes more alike a machine based, automated form of production. While car manufacturing is often used as an example of the latter, construction is often used as an example of the first. Nowhere is the effect of industrialization clearer than with the use of bathroom cabins. The cabins are produced offsite and delivered as fully equipped bathroom modules to the project, on site. They are installed already during the structural work, so that the inventory phase only includes their coupling to various technical systems (water, drain and electricity). If we were to build bathrooms on site instead, a rough estimate comprising all processes and trades sums up to about two weeks duration for each bathroom - for the inventory phase only. By the use of bathroom cabins, a major task is thereby ruled out of this phase.

There is a clear-cut resemblance between this modularized building process and the installation of dashboards in Porsche's manufacturing plant. The dashboard is installed as a complete module assisted by automated machinery, where operators do the job to connect it to the different systems in the car. In Porsche's production, there is also the car engine and propulsion system which are partly modularized, nevertheless being processed further in the factory before they are installed in the car. The final assembly otherwise includes 
prefabricated elements such as doors, lights, bumpers and so on, as well as the installing of tubes, cords and linings which are all pre-cut to fit perfectly with the car. When observing what the assembly workers do in Porsche's manufacturing plant, their operations appear as repetitive and procedural, they rely on support from automated machinery for many operations and the cells they operate are facilitated with supply of various hardware shipped onto where they stand from a storage located next to the assembly line. The housing production likewise includes the installing of pre-assembled elements such as for instance the kitchen hulls, which are put together in the kitchen manufacturing plant and delivered to the site as cabinets and drawers to be mounted on the wall. When it comes to what is going on within a process, a closer look at the crew doing the listing of doors, windows and floors may be of help. They are skilled, work in pairs and have been working together for numerous projects. The things they do are quite repetitive and procedural too, although adjusting to make things fit is also an important part of their job. For the materials they use, much of it is placed into every apartment ahead of production, in the right quantity and pre-cut.

\section{DISCUSSION: HOUSING PRODUCTION - HOW TO MAKE IT MORE LIKE MANUFACTURING}

What is the benefit of defining an apartment as the production unit? How does it assist production to know how long it takes to build an apartment? In the following, we discuss these two matters on the background of a housing project recently started up including 342 apartments. In the project, overall building costs are to be 20 per cent below the normal. Extraordinary measures are required to raise the production rate to a higher level. How come thinking of housing production in manufacturing terms should bring us any closer to achieving that goal?

By defining the apartment as the production unit, we want to turn the mindset in the work force from thinking about project completion to focusing on apartment completion. We want everyone to think in dual ways about the apartment; as a unit that is not only handed over to the next trade, but also to the residents who will live there in the end. In lean thinking, value for the customer is considered to be the ultimate goal. While the abovementioned housing project has a real estate developer as client, it also includes 342 end users. Their customer satisfaction can easily come in opposition to what we want to achieve in this project, which is to eliminate waste. The end users are allowed to make additional choices as well as changes to their apartments. Multiple choices lead to many variances of flats, on top of the different types of flats already designed in the project. To handle this product variation is about avoiding all unnecessary errors, mistakes and left outs that potentially cause tremendous amount of waste in the production. We want the trade workers to act proactively upon quality so that things are done right the first time. Defining the apartment as the production unit we expect helps delineating their quality focus. However, information must flow in a timely and updated fashion to the trade worker stepping into the apartment, as otherwise errors will occur as unintended consequences of tasks done right but based on incomplete or incorrect information. There is also the risk of human errors or mistakes. While check lists may, indeed, help ensuring the consistency 
and completeness in the carrying out of tasks, we think that by supplementing these with pictures and guidelines and sometimes even training on how to do things right the trade worker will know just what to do to. Still, errors will most likely occur. By using the apartment as the production unit, we want to trigger a proactive learning in the work force so that mistakes uncovered in one apartment are not repeated in the next one. This moreover requires systematic quality controls to be performed by each crew before the apartment is handed over to the next trade. Last but not least, we plan to hang up pictures of all the residents on the entrance door of each apartment. Every trade worker who enters can thereby say hello to those who own the apartment and suddenly faces are attached to the ones who will appreciate him or her doing a great job.

A famous quote by Henry Ford is the one saying that a customer can have a car painted in any colour as long as it's black. While the statement was made from practical concerns, it has later been used as an expression of a very standardized product. Ford had a vision to build a car for the great multitude ${ }^{4}$. The innovation competition our project won was initiated by the client from a similar desire, which was to provide "average Joe" with the opportunity to buy an apartment he would normally not afford. Defining the apartment as the production unit has helped substantially in the developing of its qualities, which are second to none at the same time as solutions sought are standardized. Ford explained his vision claiming that the car would be constructed of the best materials, by the best men to be hired, after the simplest designs that modern engineering can devise. The apartment we have designed, though being considerably more customized than the T-Ford, has been inspired by the very same ideas. One example being the supporting walls between the apartments, which are all straight to simplify the form work. When these walls are broken in corners, which they often are for architectural or other reasons, it makes them less buildable since the formwork has to be done in several stages instead of one. Another standardized solution relates to the placement of kitchen and bathroom, which in all apartments are connected directly to the shaft to simplify the technical installation. The unpractical and often costly process of pulling pipes from shafts to wet rooms and kitchens located elsewhere in the apartment, is thereby avoided. Furthermore, although we operate with altogether 28 apartment types in the project, five of these types make up 80 per cent of the apartments. We also use bathroom cabins, 3 types in all and not 30 or even 50 different types as we have in some of the other housing projects our company deliver. All in all, we have strived for an expedient design of the apartment to make it flexible in terms of letting the end user make it their own by adding qualities and making changes, at the same time as being rigid in some respects to make way for a standardized and repeated production process.

How does it assist production to know how long it takes to build an apartment? The preliminary analysis carried out in this paper has provided us with a vague idea that it takes between 70-80 days. This measure is neither very precise nor even informative to evaluate production performance. Still, questioning how long it took and attempting to find a preliminary answer made us aware of something very important. That the apartment, being

${ }^{4}$ Ford, H. (2010). My Life and Work - An Autobiography of Henry Ford. Greenbook Publications, Ilc (August $1,2010)$. 
treated as the unit of our investigation, was something that lied empty without being processed for most of the time during the inventory phase. If we were to use car manufacturing as an example of the same phenomenon, it would be as if the final assembly line was very long and at all times contained many cars waiting without being processed any further. The finding puzzled us, to the point that we thought there are two main problems by doing it this way. First, it might give the project the impression that it is busy and being on track, while the truth is, no apartment is completed yet and will not be in a long time. Second, that as long as the apartment lied empty one may come to think of it as ready for the next crew, while the fact could very well be that it contained hidden problems which were not detected before the apartment was further worked on.

We want to reduce the amount of time an apartment lies empty without being processed as waiting is waste - also when there is work waiting for people. Can work be structured differently so that the processing of the apartment can go on with less downtime? The question relates to defining how the production line should look like for the inventory phase. It implies, for our part, to do discrete analyses together with the main subcontractors. For instance, on how tasks can be put together in ways that allow for the trades to switch operations between them so that work becomes less fragmented and the number of returns are fewer for each crew. To be more concrete, why is it so that the trade worker doing the duct work has to go back to connect the extractor hood to the cabinet above the oven when the kitchen installer can do it in no time? What if the ventilation man, as a return favour to the kitchen guys, put the spice rack up in the same cabinet after installing the duct going down to the extractor hood? We also want to sort out if work can be divided more fundamentally based on it going vertically or horizontally, so that for instance the work in shafts can be started on earlier without interrupting the remaining inventory work. This would definitely help to compress the inventory phase, and likewise secure a more balanced - and less peaked - manning situation. Our point to make is this; that there are possibly several alternative ways to complete an apartment, and that reducing its downtime can be a very instructive measure to reach the most effective, and least wasteful one.

\section{CONCLUSIONS}

In this paper, the production of housings is considered from a manufacturing viewpoint. A preliminary study is carried out of the inventory phase in a housing project, using some elementary findings to clarify certain characteristics of this form of production in relation to automotive production as representative to the manufacturing type. The paper has shown that although miles apart in how they appear, the two production forms are useful to compare to trigger new thoughts about how to further improve the construction production. In particular, by using the apartment as the production unit, which is expected to bring about a more dedicated mindset in the work force around quality and completions - for the sake of the residents as well as the subsequent trade; a more expedient design of the apartment that allows for the end user to add qualities and make changes to a certain point limited by the standardized solutions chosen to make way for a repetitive production process, and; a growing awareness around what time is spent for to reduce the amount of time the apartment lies empty without being processed. 


\section{REFERENCES}

Ballard, G., and Arbulu, R. (2004). Making Prefabrication Lean. 12 ${ }^{\text {th }}$ Annual Conference of the International Group for Lean Construction, Helsingør, Denmark, 2004.

Ballard, G., and Howell, G. A. (1998). What kind of Production is Construction? $6^{\text {th }}$ Annual Conference of the International Group for Lean Construction, Guarujá, Brazil, 1998.

Ballard, G., Harper, N., and Zabelle, T. (2002). An Application of Lean Concepts and Techniques to Precast Concrete Fabrication. 10 ${ }^{\text {th }}$ Annual Conference of the International Group for Lean Construction, Gramado, Brazil, 2002.

Bertelsen, S. (2005). Modularization - a Third Approach to Making Construction Lean. $13^{\text {th }}$ Annual Conference of the International Group for Lean Construction, Sydney, Australia, 2005.

Binninger, M., Dlouhy, J., and Hagsheno, S. (2017). Technical Takt Planning and Takt Control in Construction. 25 ${ }^{\text {th }}$ Annual Conference of the International Group for Lean Construction, Heraklion, Greece, 2017.

Bølviken, T. (2012). On the Categorization of Production: The Organization-Product Matrix. $20^{\text {th }}$ Annual Conference of the International Group for Lean Construction, San Diego, USA 2012.

Ford, H. (2010). My Life and Work - An Autobiography of Henry Ford. Greenbook Publications, Ilc (August 1, 2010).

Frandson, A., Berghede, K., and Tommelein, I. D. (2013). Takt Time Planning for Construction of Exterior Cladding. $13^{\text {th }}$ Annual Conference of the International Group for Lean Construction, Fortaleza, Brazil, 2013.

Frandson, A., Seppänen. O., and Tommelein, I. D. (2015). Comparison Between Location Based Management and Takt Time Planning. 23 ${ }^{\text {rd }}$ Annual Conference of the International Group for Lean Construction, Perth, Australia, 2015.

Hermes, M. (2015). Prefabrication \& Modularization as a Part of Lean Construction Status Quo in Germany. 23rd Annual Conference of the International Group for Lean Construction, Perth, Australia, 2015.

Höök, M., and Stehn, L. (2005). Connecting Lean Construction to Prefabrication Complexity in Swedish Volume Element Housing. 13 ${ }^{\text {th }}$ Annual Conference of the International Group for Lean Construction, Sydney, Australia, 2005.

Koskela, L. (1992). Application of the new Production Philosophy to Construction. CIFE Technical Report \#72, September, 1992.

Lessing, J., Stehn, L., and Ekholm, A. (2005). Industrialised Housing: Definition and Categorisation of the Concept. $13^{\text {th }}$ Annual Conference of the International Group for Lean Construction, Sydney, Australia, 2005.

Liker, J. K., and Meier, D. (2006). The Toyota Way Fieldbook: A Practical Guide for Implementing Toyota's 4Ps. New York, London: McGraw-Hill.

Mariz, R. N., Picchi, F. A., Granja, A. D., and de Melo, R. S. S. (2012). A Review of the Standardized Work Application. 20 ${ }^{\text {th }}$ Annual Conference of the International Group for Lean Construction, San Diego, USA, 2012.

Ohno, T. (1978). Toyota Production System. Beyond Large-Scale Production. English edition by Productivity Press, New York 1988. 
Pasquire, C. L., and Connolly, G. E. (2002). Leaner Construction Through Off-Site Manufacturing. 10th Annual Conference of the International Group for Lean Construction, Gramado, Brazil, 2002.

Pasquire, C. L., and Connolly, G. E. (2003). Design for Manufacture and Assembly. 11 ${ }^{\text {th }}$ Annual Conference of the International Group for Lean Construction, Virginia, USA, 2003.Important characteristics of figures are their image type (type of file), quality (resolution), and final printed size.

Pasquire, C., Soar, R., and Gibb, A. (2006). Beyond Pre-Fabrication - the Potential of Next Generation Technologies to Make a Step Change in Construction Manufacturing. $14^{\text {th }}$ Annual Conference of the International Group for Lean Construction, Santiago, Chile, 2006.

Picchi, F. A., and Granja, A. D. (2004). Construction Sites: Using Lean Principles to Seek Broader Implementations. $12^{\text {th }}$ Annual Conference of the International Group for Lean Construction, Helsingør, Denmark, 2004.

Tillmann, P. A., and Formoso, C. T. (2008). Opportunities to Adopt Mass CustomisationA Case Study in the Brazilian House Building Sector. $16^{\text {th }}$ Annual Conference of the International Group for Lean Construction, Manchester, UK, 2008.

Vrijhof, R., and Koskela, L. (1999). Roles of Supply Chain Management in Construction. $7^{\text {th }}$ Annual Conference of the International Group for Lean Construction, Berkeley, USA, 1999.

Zimmer, E., Salem, O., Genaidy, A., and Shell, R. (2008). Case Study: Lean Supply Chain Management in Construction. $16^{\text {th }}$ Annual Conference of the International Group for Lean Construction, Manchester, UK, 2008. 